OPEN ACCESS

Edited by:

Jose Maria Prieto,

University College London,

United Kingdom

Reviewed by:

Fang-Rong Chang,

Kaohsiung Medical University, Taiwan

Sevser Sahpaz,

Lille 2 University, France

*Correspondence:

Angela Ladurner

angela.ladurner@univie.ac.at

Specialty section:

This article was submitted to

Ethnopharmacology,

a section of the journal

Frontiers in Pharmacology

Received: 24 February 2017 Accepted: 30 June 2017

Published: 17 July 2017

Citation:

Ladurner A, Zehl M, Grienke U, Hofstadler C, Faur N, Pereira FC, Berry D, Dirsch VM and Rollinger JM (2017) Allspice and Clove As Source of Triterpene Acids Activating the $G$ Protein-Coupled Bile Acid Receptor TGR5. Front. Pharmacol. 8:468. doi: 10.3389/fphar.2017.00468

\section{Allspice and Clove As Source of Triterpene Acids Activating the G Protein-Coupled Bile Acid Receptor TGR5}

\author{
Angela Ladurner ${ }^{1 *}$, Martin Zehl',2,3, Ulrike Grienke ${ }^{1}$, Christoph Hofstadler ${ }^{1}$, Nadina Faur ${ }^{1}$, \\ Fátima C. Pereira ${ }^{4}$, David Berry ${ }^{4}$, Verena M. Dirsch ${ }^{1}$ and Judith M. Rollinger ${ }^{1}$ \\ 'Department of Pharmacognosy, Faculty of Life Sciences, University of Vienna, Vienna, Austria, ${ }^{2}$ Department of \\ Pharmaceutical Chemistry, University of Vienna, Vienna, Austria, ${ }^{3}$ Department of Analytical Chemistry, University of Vienna, \\ Vienna, Austria, ${ }^{4}$ Department of Microbiology and Ecosystem Science, University of Vienna, Vienna, Austria
}

Worldwide, metabolic diseases such as obesity and type 2 diabetes have reached epidemic proportions. A major regulator of metabolic processes that gained interest in recent years is the bile acid receptor TGR5 (Takeda G protein-coupled receptor 5). This $G$ protein-coupled membrane receptor can be found predominantly in the intestine, where it is mainly responsible for the secretion of the incretins glucagon-like peptide 1 (GLP-1) and peptide YY (PYY). The aim of this study was (i) to identify plant extracts with TGR5-activating potential, (ii) to narrow down their activity to the responsible constituents, and (iii) to assess whether the intestinal microbiota produces transformed metabolites with a different activity profile. Chenodeoxycholic acid (CDCA) served as positive control for both, the applied cell-based luciferase reporter gene assay for TGR5 activity and the biotransformation assay using mouse fecal slurry. The suitability of the workflow was demonstrated by the biotransformation of CDCA to lithocholic acid resulting in a distinct increase in TGR5 activity. Based on a traditional Tibetan formula, 19 plant extracts were selected and investigated for TGR5 activation. Extracts from the commonly used spices Syzygium aromaticum (SaroE, clove), Pimenta dioica (PdioE, allspice), and Kaempferia galanga (KgalE, aromatic ginger) significantly increased TGR5 activity. After biotransformation, only KgalE showed significant differences in its metabolite profile, which, however, did not alter its TGR5 activity compared to non-transformed KgalE. UHPLC-HRMS (high-resolution mass spectrometry) analysis revealed triterpene acids (TTAs) as the main constituents of the extracts SaroE and PdioE. Identification and quantification of TTAs in these two extracts as well as comparison of their TGR5 activity with reconstituted TTA mixtures allowed the attribution of the TGR5 activity to TTAs. $\mathrm{EC}_{50} \mathrm{~s}$ were determined for the main TTAs, i.e., oleanolic acid $(2.2 \pm 1.6 \mu \mathrm{M})$, ursolic acid $(1.1 \pm 0.2 \mu \mathrm{M})$, as well as for the hitherto unknown TGR5 activators corosolic acid $(0.5 \pm 1.0 \mu \mathrm{M})$ and maslinic acid $(3.7 \pm 0.7 \mu \mathrm{M})$. In conclusion, extracts of clove, allspice, and aromatic ginger activate TGR5, which might play a pivotal role in their therapeutic use for the treatment of metabolic diseases. Moreover, the TGR5 activation of SaroE and PdioE could be pinpointed solely to TTAs.

Keywords: TGR5, Syzygium aromaticum, Pimenta dioica, Kaempferia galanga, triterpene acids 


\section{INTRODUCTION}

The bile acid receptor TGR5 [Takeda G protein-coupled receptor 5 , also known as $G$ protein-coupled bile acid receptor 1 (GPBAR1) or membrane-type receptor for bile acids (M-BAR)] is expressed in a wide variety of tissues and cell types including the intestine, gallbladder, adipocytes, and immune cells and is considered to be a major regulator in metabolism. TGR5 acts in a tissue-specific manner via increasing intracellular levels of cAMP and thereby modulating several downstream signaling pathways (Kawamata et al., 2003; Thomas et al., 2008). Activation of TGR5 has been shown to enhance insulin secretion in the pancreas (Kumar et al., 2012) as well as gallbladder filling (Li et al., 2011). In addition, TGR5 influences bile acid pool size and composition (Maruyama et al., 2006) and has been shown to be nephroprotective in models of diabetes and obesity (Wang et al., 2016). In immune cells, TGR5 agonists show anti-inflammatory activities (Wang et al., 2011; Yoneno et al., 2013), whereas in enteroendocrine cells, release of the incretins glucagon-like peptide 1 (GLP-1) and peptide YY (PYY) is stimulated (Thomas et al., 2009; Harach et al., 2012; Bala et al., 2014). Furthermore, in muscle and brown adipose tissue, TGR5 agonists are able to increase energy expenditure (Watanabe et al., 2006; Svensson et al., 2013; Broeders et al., 2015) and in the enteric nervous system, gastric emptying is delayed and gut motility decreased (Poole et al., 2010). This multitude of effects renders TGR5 a promising target for the treatment of metabolic diseases (Perino and Schoonjans, 2015).

This prompted us to select and study plant extracts derived from a Tibetan herbal preparation, which is used against different symptoms of metabolic diseases (Brunner-La Rocca et al., 2005; Melzer et al., 2006; Melzer and Saller, 2013; Schwabl and Vennos, 2015).

Since TGR5 is abundantly expressed in the intestine, which facilitates local interactions between plant constituents and various components present in the gut, we also considered the possibility of microbiota-mediated biotransformation of extract constituents. Biotransformation by microorganisms residing in the gastrointestinal tract holds significant potential for the discovery of bioactive compounds (Saha et al., 2016). Components of food or herbal drugs that are not absorbed in the upper intestinal tract are able to reach the large intestine, where most of the gut microbiome resides (AronWisnewsky et al., 2012). Gut microorganisms possess an arsenal of enzymes that are able to chemically modify a large variety of compounds, including plant secondary metabolites, thereby allowing the formation of new compounds with potentially diverging bioactivities. Typical examples for such enzyme-catalyzed reactions are the hydrolysis of glycosides (e.g., by $\alpha$-rhamnosidase, $\beta$-glucuronidase, $\beta$-glucosidase) and esters (e.g., by sulfatases, carboxylesterase), reduction, oxidation, dehydroxylation, demethylation, decarboxylation, dehydrogenation, and various isomerizations (Possemiers et al., 2011).

Thus, the aims of this study were (i) to identify plant extracts which are able to activate TGR5 in vitro, (ii) to identify the active components in the respective original and biotransformed plant extracts, and (iii) to monitor the metabolite profile of TGR5activating extracts considering putative biotransformation of the herbal constituents by incubation with mouse fecal microbiota.

\section{MATERIALS AND METHODS}

\section{Reference and Standard Compounds}

Maslinic acid, corosolic acid, oleanolic acid, and ursolic acid were obtained from Phytolab (Vestenbergsgreuth, Germany), lithocholic acid (LCA), chenodeoxycholic acid (CDCA), oleic acid, and palmitic acid from Sigma Aldrich (St. Louis, MO, United States), stearic acid and 4-methoxycinnamic acid from Fluka (Buchs, Switzerland), chlorogenic acid from Carl Roth (Karlsruhe, Germany), and linoleic acid from Acros (Geel, Belgium). Eugenol was isolated from clove and the identity and purity tested by ATR-IR spectroscopy. All reference and standard compounds were obtained in a purity of $\geq 90 \%$. They were dissolved to $1.0 \mathrm{mg} / \mathrm{mL}$ in $\mathrm{MeOH}$. The triterpene acids (TTAs) used for the quantification were mixed and diluted to give a standard solution containing $100 \mu \mathrm{g} / \mathrm{mL}$ of each corosolic acid, maslinic acid, oleanolic acid, and ursolic acid followed by a serial dilution down to $2 \mu \mathrm{g} / \mathrm{mL}$.

\section{Cell Culture Reagents, Chemicals, and Plasmids}

Dulbecco's modified Eagle's medium (DMEM), containing $4.5 \mathrm{~g} / \mathrm{L}$ glucose, L-glutamine, benzylpenicillin, and streptomycin were obtained from Lonza (Basel, Switzerland). Fetal bovine serum (FBS) and trypsin was supplied by Gibco via Invitrogen (Lofer, Austria). The TGR5 expression plasmid, GPBAR1, transcript variant 3, NM_170699.1 (OG-SC123315) was obtained from Origene via Biomedica (Vienna, Austria). The CRELuc plasmid, pGL4.29[luc2P/CRE/Hygro], was obtained from Promega (Mannheim, Germany) and the plasmid encoding enhanced green fluorescence protein (pEGFP-N1) was obtained from Clontech (Mountain View, CA, United States).

\section{Plant Material}

Dried and powdered herbal material was kindly provided by PADMA AG (Wetzikon, Switzerland). Information regarding the used organ, plant species, batch number, and acronym of the prepared extracts are given in Table 1. Voucher specimens are deposited at the Department of Pharmacognosy, University of Vienna, Austria.

\section{Extraction and Tannin Depletion}

Small scale extraction was adapted from Camp et al. (2012) as previously described (Kratz et al., 2016). In brief, $300 \mathrm{mg}$ plant material was defatted with $n$-hexane before subsequent extraction with $\mathrm{CH}_{2} \mathrm{Cl}_{2}(7 \mathrm{~mL})$ and $\mathrm{MeOH}(13 \mathrm{~mL})$ for $15 \mathrm{~min}$ each by ultrasonication. The combined and dried extracts were resuspended in $4 \mathrm{~mL} \mathrm{MeOH}$ and loaded onto a SPE polyamide gel cartridge for tannin depletion. The flow-through and eluate from washing with $2 \times 4 \mathrm{~mL} \mathrm{MeOH}$ was combined and dried under reduced pressure. Dried extracts were dissolved in 
TABLE 1 | Information regarding the used plant material for extract preparation (including extract acronym).

\begin{tabular}{|c|c|c|c|c|}
\hline Acronym of the extract & Plant species & Used organ & English name & Batch number \\
\hline AmarE & Aegle marmelos (L.) Correa & Half-ripe entire fruits & Bael tree fruit & 20982301 \\
\hline AvulE & Aquilegia vulgaris L. & Aerial parts & Columbine & 21290300 \\
\hline AindE & Azadirachta indica A. Juss & Endocarp and seeds & Neem fruit & 21108301 \\
\hline CoffE & Calendula officinalis L. & Entire flowering part & Marigold & 21348300 \\
\hline CislE & Cetraria islandica (L.) Acharius s.I. & Thallus & Iceland moss & 20885300 \\
\hline EcarE & Elettaria cardamomum (Roxb.) Maton var. minuscula Burkill & Entire fruits (including seeds) & Cardamom fruit & 21391101 \\
\hline GglaE & Glycyrrhiza glabra L. & Roots and stolons & Liquorice root & 21392100 \\
\hline KgalE & Kaempferia galanga L. & Rhizomes & aromatic ginger & 21345300 \\
\hline LsatE & Lactuca sativa var. capitata L. & Leaves & Lettuce leave & 21400300 \\
\hline PlanE & Plantago lanceolata L. s.I. & Leaf and scape & Ribwort plantain & 21327101 \\
\hline PdioE & Pimenta dioica (L.) Merr. & Unripe fruits & Allspice & 21362100 \\
\hline PaviE & Polygonum aviculare L. s.I. & Aerial parts & Knotgrass & 21322100 \\
\hline PaurE & Potentilla aurea L. & Aerial parts & Potentilla golden herb & 21161301 \\
\hline PsanE & Pterocarpus santalinus L.f. & Heartwood & Red sandalwood & 20712307 \\
\hline ScosE & Saussurea costus (Falc.) Lipschitz & Roots & Costus root & 21280300 \\
\hline ScorE & Sida cordifolia L. & Aerial parts & Heart-leaved sida & 20981300 \\
\hline SaroE & Syzygium aromaticum (L.) Merr. \& L. M. Perry & Flower buds & Clove & 21321101 \\
\hline TcheE & Terminalia chebula Rertz & Fruits & Myrobalan fruit & 21324301 \\
\hline VoffE & Valeriana officinalis L. s.I. & Rhizomes, roots and stolons & Valerian root & 21388100 \\
\hline
\end{tabular}

dimethyl sulfoxide (DMSO) prior to bioactivity measurements. For bioassays, the final DMSO concentration was $0.1 \%$.

\section{Fractionation of the Kaempferia galanga Extract (KgalE)}

To produce sufficient amounts of extract for further fractionation, the whole extraction and tannin-depletion procedure (see above) was scaled up by a factor of 10 . The obtained extract (KgalE, $70 \mathrm{mg}$ ) was then fractionated by flash chromatography (PuriFlash 4250 system, Interchim, Montlucon Cedex, France) on a PuriFlash column (PF-RPC18HQ, $15 \mu \mathrm{m}$, $6 \mathrm{~g}$, Interchim) using water and acetonitrile as mobile phases $\mathrm{A}$ and $\mathrm{B}$, respectively. The sample was applied as dry load onto the PuriFlash column and eluted at $25^{\circ} \mathrm{C}$ with a flow rate of $5 \mathrm{~mL} / \mathrm{min}$ and a linear gradient of 5-95\% B in $45 \mathrm{~min}$. Eluting compounds were detected with both, a UV-detector (200-400 nm) and an evaporative light-scattering detector (ELSD). Six fractions (KgalE-1 to 6) were collected based on the ELSD signal followed by TLC monitoring (stationary phase: Merck silica gel $60 \mathrm{PF}_{254}$; mobile phase: toluol/ethyl acetate/formic acid/methanol/acetone, 4:2:1:0.5:0.25:0.25; detection with staining reagents vanillin $/ \mathrm{H}_{2} \mathrm{SO}_{4}$ at vis, $\mathrm{UV}_{254}, \mathrm{UV}_{366}$ ), with the following elution volumes: KgalE-1, 90-138 mL; KgalE-2, 138-204 mL; KgalE-3, 204-237 mL; KgalE-4, 237-261 mL; KgalE-5, 267-327 mL; KgalE-6, 327-351 mL.

\section{Preparation and Analysis of the Essential oil of $K$. galanga}

Essential oil of $K$. galanga was obtained by small-scale steam distillation of $2.0 \mathrm{~g}$ of the dried and pulverized drug with $20 \mathrm{~mL}$ of water for $1.5 \mathrm{~h}$. The main constituents of the volatile oil were identified by GC-MS (mass spectrometry) on a QP2010 System (Shimadzu Austria, Korneuburg, Austria) equipped with a Zebron ZB-5 capillary column (60 m length, $0.25 \mu \mathrm{m}$ film thickness; Phenomenex, Aschaffenburg, Germany). One microliter of the diluted essential oil $\left(1: 100\right.$ in $\left.\mathrm{CH}_{2} \mathrm{Cl}_{2}\right)$ was injected and separated with $\mathrm{He}(5.0)$ as carrier gas applying a temperature gradient from 50 to $270^{\circ} \mathrm{C}$ in $45 \mathrm{~min}$. EI mass spectra were recorded in the range of $m / z 40-500$. The chemical composition in terms of normalized \% peak area was determined on an AutoSystem XL equipped with a SE-54-CB capillary column (10 m length, $0.25 \mu \mathrm{m}$ film thickness) and an FID detector. In this case, $\mathrm{N}_{2}$ (5.0) was used as carrier gas and the temperature was increased from 50 to $155^{\circ} \mathrm{C}$ in $35 \mathrm{~min}$.

\section{Biotransformation of Plant Extracts by Mouse Fecal Slurry}

Simulated gastric fluid (SGF) was prepared according to the European Pharmacopoeia (Ph. Eur. 8th): $2.0 \mathrm{~g} \mathrm{NaCl}$ were dissolved in water. Eighty milliliters of $1 \mathrm{M} \mathrm{HCl}$ were added and the solution was diluted with water to achieve $1000 \mathrm{~mL}$ solution $(\mathrm{pH}=1.2)$. Neutralization to a $\mathrm{pH}$ of $\sim 7$ after incubation was achieved by adding diluted $\mathrm{NaOH}$ (Ph. Eur. 8; 8.5 g NaOH dissolved in water to achieve a $100 \mathrm{~mL}$ solution). Phosphatebuffered saline (PBS) was prepared with $137 \mathrm{mM} \mathrm{NaCl}, 2.7 \mathrm{mM}$ $\mathrm{KCl}, 10 \mathrm{mM} \mathrm{Na}_{2} \mathrm{HPO}_{4}$, and $1.8 \mathrm{mM} \mathrm{KH}_{2} \mathrm{PO}_{4}$ to achieve a $\mathrm{pH}$ of 7.4 .

Fecal slurry was prepared with fecal pellets obtained from C57BL/6 wild type mice (kindly provided by the Max F. Perutz Laboratories Animal Facility, Vienna). All procedures involving animal handling and sampling were performed according to protocols approved by the Austrian law (BMWF $68.205 / 0032-\mathrm{WF} / \mathrm{II} / 3 \mathrm{~b} / 2014)$. Handling of the animals for sample collection was carried out by FELASA B degree holding personnel. Freshly evacuated fecal pellets were collected from mice that were housed together in the same cage, and 
immediately stored into an Oxoid ${ }^{\mathrm{TM}}$ Anaerobic $3.5 \mathrm{~L}$ jar, where oxygen is removed by the presence of a AnaeroGen sachet (Thermo Scientific AN0035). The jar containing the fecal pellets was then introduced in a Vinyl Anaerobic Chamber (Coy Laboratory Products). Fecal pellets $(\sim 12)$ were resuspended in $18 \mathrm{~mL}$ of PBS, and used instantly after preparation. For control samples (labeled with superscript 0), suspended fecal slurry was autoclaved before incubation.

Dried tannin-depleted extracts $(4 \mathrm{mg})$ or CDCA (100 nmol) were incubated with $1 \mathrm{~mL} \mathrm{SGF}$ for $90 \mathrm{~min}$ at $37^{\circ} \mathrm{C}$ followed by neutralization with diluted $\mathrm{NaOH}$. Then, $1 \mathrm{~mL}$ of either autoclaved or non-autoclaved fecal slurry was added followed by incubation for $24 \mathrm{~h}$ at $37^{\circ} \mathrm{C}$ under anaerobic conditions. The incubation was terminated by adding ethanol to a final concentration of $48 \mathrm{vol} \%$ ethanol followed by storage at $-20^{\circ} \mathrm{C}$ for about $18 \mathrm{~h}$. Centrifugation and sterile filtration were applied before subjecting the samples to analytical and pharmacological investigations.

\section{Identification of the Main Constituents in the Extracts and Fractions by HPLC-DAD-CAD and LC-MS}

To identify the TGR5-activating compounds, samples were analyzed by high-performance liquid chromatography (HPLC) with charged aerosol detection (CAD) and HPLC-MS. These analyses were performed on an UltiMate 3000 RSLC-series system (Dionex/Thermo Fisher Scientific, Germering, Germany) coupled in parallel to a Corona ultra RS charged aerosol detector (CAD, Dionex/Thermo Fisher Scientific) and an HCT 3D quadrupole ion trap mass spectrometer equipped with an orthogonal ESI source (Bruker Daltonics, Bremen, Germany). Separation was carried out on an Acclaim $120 \mathrm{C} 18$, $2.1 \mathrm{~mm} \times 150 \mathrm{~mm}, 3 \mu \mathrm{m}$ HPLC column (Dionex/Thermo Fisher Scientific) using $0.1 \%$ aqueous formic acid and acetonitrile as mobile phase $\mathrm{A}$ and $\mathrm{B}$, respectively. The gradient was slightly modified for each extract (Syzygium aromaticum: $5-25 \%$ B in $10 \mathrm{~min}, 25-65 \%$ B in $8 \mathrm{~min}, 65-89 \%$ B in $12 \mathrm{~min}$, and $89-95 \%$ B in $1 \mathrm{~min}$; Pimenta dioica: $5-26 \% \mathrm{~B}$ in $14 \mathrm{~min}, 26-75 \% \mathrm{~B}$ in $14 \mathrm{~min}$, and $75-95 \%$ B in $10 \mathrm{~min}$; K. galanga: $5-95 \%$ B in $45 \mathrm{~min})$. Each gradient was followed by a washing $(10 \mathrm{~min}$ at $95 \% \mathrm{~B})$ and reequilibration step ( $10 \mathrm{~min}$ at $5 \% \mathrm{~B}$ ). The flow rate was $0.5 \mathrm{~mL} / \mathrm{min}$ and the column oven temperature was set to $25^{\circ} \mathrm{C}$. After passing the diode-array detector (DAD), the eluate flow was split 4:1 between the CAD and the MS, respectively. The CAD nebulizer temperature was $35^{\circ} \mathrm{C}$ and the ESI ion source was operated as follows: capillary voltage: $+3.5 /-3.7 \mathrm{kV}$, nebulizer: 26 psi $\left(\mathrm{N}_{2}\right)$, dry gas flow: $9 \mathrm{~L} / \mathrm{min}\left(\mathrm{N}_{2}\right)$, and dry temperature: $340^{\circ} \mathrm{C}$. Positive and negative ion mode multistage mass spectra up to $\mathrm{MS}^{3}$ were obtained in automated data-dependent acquisition (DDA) mode using helium as collision gas, an isolation window of $\Delta m / z=4$, and a fragmentation amplitude of $1.0 \mathrm{~V}$.

To confirm the tentative identifications achieved with the above system, high-resolution mass spectra were recorded on a maXis HD ESI-Qq-TOF mass spectrometer (Bruker Daltonics) that was also connected to an UltiMate 3000 RSLC-series system. The separation was performed with the above-described HPLC methods. The eluate flow was split approximately 1:8 and the following ESI ion source settings were applied: capillary voltage: $\pm 4.5 \mathrm{kV}$, nebulizer: 0.8 bar $\left(\mathrm{N}_{2}\right)$, dry gas flow: $7.0 \mathrm{~L} / \mathrm{min}\left(\mathrm{N}_{2}\right)$, and dry temperature: $200^{\circ} \mathrm{C}$. The sum formulas of the detected ions were determined using Bruker Compass DataAnalysis 4.2 based on the mass accuracy $(\Delta m / z \leq 10 \mathrm{ppm})$ and isotopic pattern matching (SmartFormula algorithm).

\section{Quantification of the Main Triterpene Acids in Extracts of S. aromaticum (SaroE) and P. dioica (PdioE)}

The main TTAs in SaroE and PdioE were quantified with the above-described HPLC-DAD-CAD system using external calibration. While the same stationary and mobile phase was applied as for the identification, other parameters had to be adapted to achieve better separation of the analytes: the flow rate was set to $0.3 \mathrm{~mL} / \mathrm{min}$, the column oven temperature to $10^{\circ} \mathrm{C}$; the gradient consisted of a linear increase from 80 to $91 \%$ B in 22 min (followed by a column cleaning and a reequilibration step). The extracts, quantification standards (100, $40,20,10,5$, and $2 \mu \mathrm{g} / \mathrm{mL}$ each of corosolic acid, maslinic acid, oleanolic acid, and ursolic acid), a quality control sample (12 $\mu \mathrm{g} / \mathrm{mL}$ each of corosolic acid, maslinic acid, oleanolic acid, and ursolic acid) and a blank sample (pure $\mathrm{MeOH}$ ) were analyzed in quadruplicates. For each analyte, the peak area was obtained from the CAD chromatograms and a linear calibration function was determined from the quantification standards, which was then used to calculate the concentration of the four TTAs in the active extracts.

\section{TGR5 Luciferase Reporter Gene Assay}

For the TGR5 luciferase reporter gene assay HEK-293 cells (ATCC, Manassas, VA, United States) were maintained in DMEM containing $4.5 \mathrm{~g} / \mathrm{L}$ glucose supplemented with $2 \mathrm{mM}$ glutamine, $10 \%$ FBS, $100 \mathrm{U} / \mathrm{mL}$ benzylpenicillin and $100 \mu \mathrm{g} / \mathrm{mL}$ streptomycin. Cells were grown in $15 \mathrm{~cm}$ dishes at a density of $6 \times 10^{6}$ cells per dish for $19 \mathrm{~h}$ and then transfected via the calcium phosphate precipitation method with $5 \mu \mathrm{g}$ TGR5 expression plasmid, $5 \mu \mathrm{g}$ CRE-Luc plasmid, and $3 \mu \mathrm{g}$ of a plasmid encoding EGFP as internal control. After $6 \mathrm{~h}$ the cells were reseeded to 96 -well plates $\left(5 \times 10^{4}\right.$ cells/well $)$ in DMEM containing $4.5 \mathrm{~g} / \mathrm{L}$ glucose supplemented with $2 \mathrm{mM}$ glutamine, $100 \mathrm{U} / \mathrm{mL}$ benzylpenicillin, $100 \mu \mathrm{g} / \mathrm{mL}$ streptomycin, and 5\% charcoal-stripped FBS. Cells were treated with indicated concentrations of test extracts, positive control (10 $\mu \mathrm{M}$ LCA) or solvent vehicle $(0.1 \%$ DMSO) and incubated for $18 \mathrm{~h}$. Cells were then lysed and the luminescence of the firefly luciferase and the fluorescence of EGFP were quantified with a GeniosPro plate reader (Tecan, Grödig, Austria). The luciferase-derived luminescence was normalized to the EGFP-derived fluorescence from each well to account for differences in transfection efficiency or cell number.

\section{Statistical Analysis}

Statistical analyses were performed with the GraphPad prism software version 4.03. Non-linear regression (sigmoidal dose 
response) was used to calculate the $\mathrm{EC}_{50}$ values and maximal fold activation. The data are presented as the mean \pm SD. Statistical evaluation was performed by one-way analysis of variance (ANOVA) and Student's $t$-test. Differences between groups with a $p$-value $<0.05$ were considered statistically significant.

\section{RESULTS}

\section{Plant Selection}

Nineteen herbal drugs of a Tibetan formula used against different symptoms associated with the metabolic syndrome were selected and tested for their potential to activate TGR5. The formula contains the pulverized material of the following plant materials: costus root, Iceland moss, neem fruit, cardamom fruit, myrobalan fruit, red sandalwood, allspice, bael tree fruit, columbine, liquorice root, ribwort plantain, knotgrass, potentilla golden herb, clove, aromatic ginger, heart-leaved sida, valerian root, lettuce leaf, and marigold.

In accordance to the oral application of the pulverized material, extracts were prepared as previously described (Kratz et al., 2016) by a protocol adapted from Camp et al. (2012). Herein, defatted plant material is extracted successively with dichloromethane and methanol. The two resulting extracts were combined in order to cover drug-like properties in a wide range of polarity. Further, tannin depletion via polyamide gel was carried out in order to remove common assay-interfering compounds.

\section{TGR5 Activation by Extracts of $P$. dioica (PdioE), S. aromaticum (SaroE), and K. galanga (KgalE)}

The obtained extracts were screened in HEK-293 cells transfected with the TGR5 receptor and a luciferase gene containing the respective response element in its promoter (CRE-Luc). Three plant extracts were able to significantly activate TGR5 at concentrations of 100 and $30 \mu \mathrm{g} / \mathrm{mL}$, namely those of the dried flower buds of $S$. aromaticum (SaroE), commonly known as cloves, the unripe fruits of $P$. dioica (PdioE), commonly known as allspice, and the rhizomes of $K$. galanga (KgalE), known as aromatic ginger. These three medicinal plants are used as herbal remedies for the treatment of digestive problems, diabetes, as antioxidants and analgesics in traditional medicines, especially of Middle Eastern and Asian countries as well as the Caribbean (Achuthan and Padikkala, 1997; Zhang and Lokeshwar, 2012; Kumar et al., 2013; Cortes-Rojas et al., 2014; Opara and Chohan, 2014; Sanae et al., 2014; Tu et al., 2014). Interestingly, all three herbal drugs are also widely used as spices.

Concentration-response studies were performed with the three TGR5-activating extracts PdioE, SaroE, and KgalE to determine their $\mathrm{EC}_{50}$ and $E_{\max }$ values. As reference compound, the well-established TGR5 agonist LCA (Figure 1) was used at a concentration of $10 \mu \mathrm{M}$, which was set as $100 \%$ TGR5 activation. The assay was validated with CDCA (Figure 1), which showed an $\mathrm{EC}_{50}$ of $33.2 \pm 4.5 \mu \mathrm{M}$ with $34.6 \pm 8.6 \%$ maximum relative TGR5 activation in our assay. All three plant extracts were able to increase TGR5 activity in a concentration-dependent manner; KgalE showed the lowest $\mathrm{EC}_{50}$ with $12.9 \pm 24.1 \mu \mathrm{g} / \mathrm{mL}$ and an $E_{\max }$ of $33.2 \pm 4.5 \%$ compared to LCA (Figure 2A and Table 2). PdioE elicited an $E_{\max }$ of $29.5 \pm 8.3 \%$ compared to LCA and the highest $\mathrm{EC}_{50}$ of all three plant extracts with $60.2 \pm 13.7 \mu \mathrm{g} / \mathrm{mL}$ (Figure 2B). Intriguingly, SaroE revealed the highest efficiency with an $E_{\max }$ of $112.8 \pm 12.1 \%$ compared to LCA, overreaching by far the efficiency of our positive control CDCA. The $\mathrm{EC}_{50}$ of SaroE was determined to be $19.8 \pm 16.6 \mu \mathrm{g} / \mathrm{mL}$ (Figure $2 \mathrm{C}$ and Table 2).

\section{Microbial Transformation of CDCA and Plant Extracts}

To simulate the passage of orally ingested compounds through the gastrointestinal system, the positive control CDCA and the prepared extracts were first suspended in SGF and incubated for $90 \mathrm{~min}$ to account for the physiological retention time in the stomach. After neutralization of this mixture with sodium hydroxide, either (i) deactivated fecal microbiota (i.e., nontransformed, labeled with superscript 0), or (ii) active fecal microbiota (i.e., transformed, superscript FS) from mice were added to facilitate the biotransformation of the constituents.

Incubation of the positive control CDCA with mouse fecal microbiota led to a strong biotransformation, thus proving the suitability of the experimental workflow. HPLC-DAD-CAD and LC-MS analyses showed that about half of the CDCA was consumed after $24 \mathrm{~h}$ while at least four different metabolites were produced (Supplementary Figure S1), presumably by 7-dehydroxylation, 3- or 7-dehydrogenation, and 3- or 7epimerization as previously described (Gerard, 2013). After $24 \mathrm{~h}$ incubation, the most abundant metabolite was identified as LCA by comparison with a reference standard. LCA is the most potent endogenous agonist for TGR5 with CDCA being significantly less active (Kawamata et al., 2003). To evaluate our assay system, CDCA was incubated with active and deactivated fecal slurry for $24 \mathrm{~h}\left(\mathrm{CDCA}^{\mathrm{FS}}\right.$ and $\mathrm{CDCA}^{0}$, respectively). In accordance with the observed transformation, $\mathrm{CDCA}^{\mathrm{FS}}$ elicited a much higher response than $\mathrm{CDCA}^{0}$ in the TGR5 luciferase reporter gene assay (Figure 3).

Instrumental analysis of the transformed $\left(\mathrm{KgalE}^{\mathrm{FS}}, \mathrm{SaroE}^{\mathrm{FS}}\right.$, and $\mathrm{PdioE}{ }^{\mathrm{FS}}$ ) and non-transformed extracts $\left(\mathrm{KgalE}^{0}, \mathrm{SaroE}^{0}\right.$, and $\mathrm{PdioE}^{0}$ ) revealed that only PdioE and KgalE showed differences in the metabolite profile after transformation. In both cases, an increase in the abundance of compounds that were tentatively identified as free fatty acids and hydroxylated or otherwise oxidized fatty acids was detected, which can be explained by the action of lipolytic enzymes on remaining polar lipids in the extracts. For PdioE, it was additionally observed that a compound tentatively identified as ericifolin (Shamaladevi et al., 2013) by high-resolution mass spectrometry (HRMS) and fragment ion spectra was completely degraded after $24 \mathrm{~h}$ of incubation with mouse fecal microbiota. The comparison of $\mathrm{KgalE}^{0}$ and $\mathrm{KgalE}^{\mathrm{FS}}$ showed a marked increase in the abundance of 4-methoxycinnamic acid, presumably by hydrolysis of larger phenylpropanoid structures, and higher concentrations of some not unambiguously identified small polar metabolites. 
<smiles>C[C@H](CCC(=O)O)[C@H]1CC[C@H]2[C@@H]3CC[C@H]4C[C@@H](O)CC[C@]4(C)C3CC[C@@]21C</smiles>

lithocholic acid (LCA)

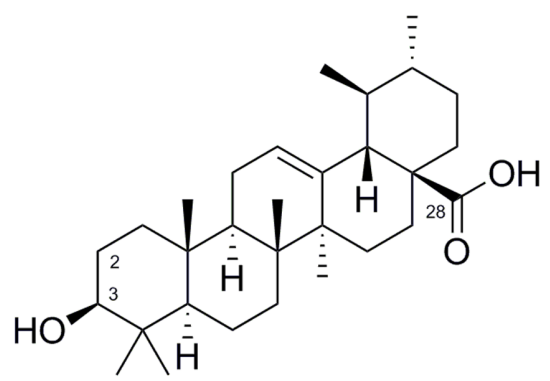

ursolic acid<smiles>CC1(C)CC[C@]2(C(=O)O)CC[C@H]3C(=CCC4[C@@]3(C)CC[C@H]3C(C)(C)[C@H](O)[C@@H](O)C[C@]43C)[C@]2(C)C1</smiles>

maslinic acid

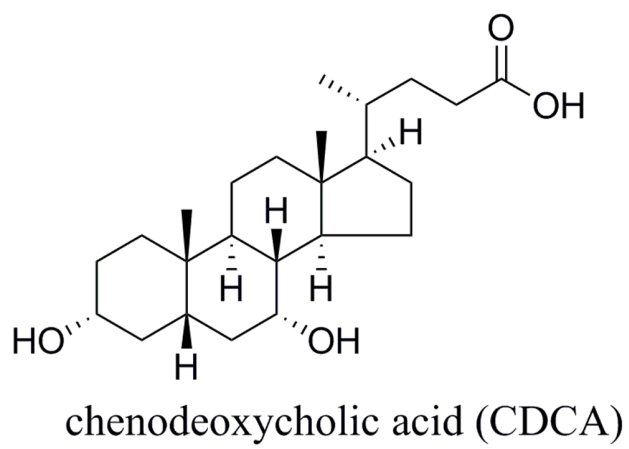<smiles>CC1(C)CC[C@]2(C(=O)O)CC[C@H]3C(=CCC4[C@@]3(C)CC[C@H]3C(C)(C)[C@H](O)CC[C@]43C)[C@]2(C)C1</smiles>

oleanolic acid

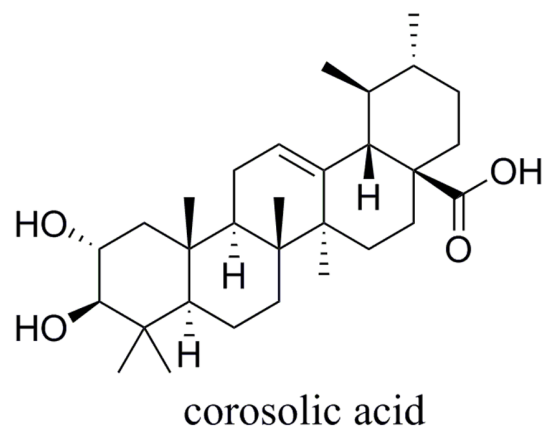

FIGURE 1 | Chemical structures of lithocholic acid (LCA), chenodeoxycholic acid (CDCA), and TTAs.

To elucidate a possible impact caused by incubation with fecal slurry, KgalE and PdioE were retested for their TGR5activating potential, once incubated with active fecal slurry and once prepared with deactivated fecal slurry. However, other than in the case of CDCA, no significant difference in activity using the TGR5 reporter gene assay could be observed between $\mathrm{KgalE}^{0}$ and $\mathrm{KgalE}^{\mathrm{FS}}$, and $\mathrm{PdioE}^{0}$ and $\mathrm{PdioE}^{\mathrm{FS}}$, suggesting that the analytically observed biotransformation has no influence on the TGR5 activity. Therefore, we further focused on the identification of plant metabolites not targeted and modified by the fecal microbiota.

\section{Dereplication of the Main Constituents in the Active Extracts KgalE, SaroE, and \\ PdioE}

To identify the compounds responsible for TGR5 activity, all three active extracts were analyzed by HPLC and LC-MS. The accurate masses of the individual compounds were determined by HPLC-HRMS on an ESI-QqTOF system. Sum formulas were predicted based on mass accuracy $(\Delta m / z \leq 10 \mathrm{ppm})$ and isotopic pattern matching. Finally, structural information was obtained by HPLC-multistage $\mathrm{MS}\left(\mathrm{MS}^{n}\right)$ on an ESIion trap system in DDA mode. Since all three plant species represent prominent spices and herbal drugs, they are well studied in terms of their chemical constituents. Thus, the main compounds could be tentatively identified as known metabolites of the investigated plant parts (see Tables 3-5 and Supplementary Figures S2-S4 in the Supporting Information). The assignment of several of these structures was confirmed by comparison of the retention time and spectral data with reference standards.

All three extracts contained common fatty acids (e.g., palmitic, stearic, oleic, and linolenic acids) as well as cyclic oligomers of $\varepsilon$-caprolactam-the latter being non-TGR5-influencing artifacts from the extract preparation. 

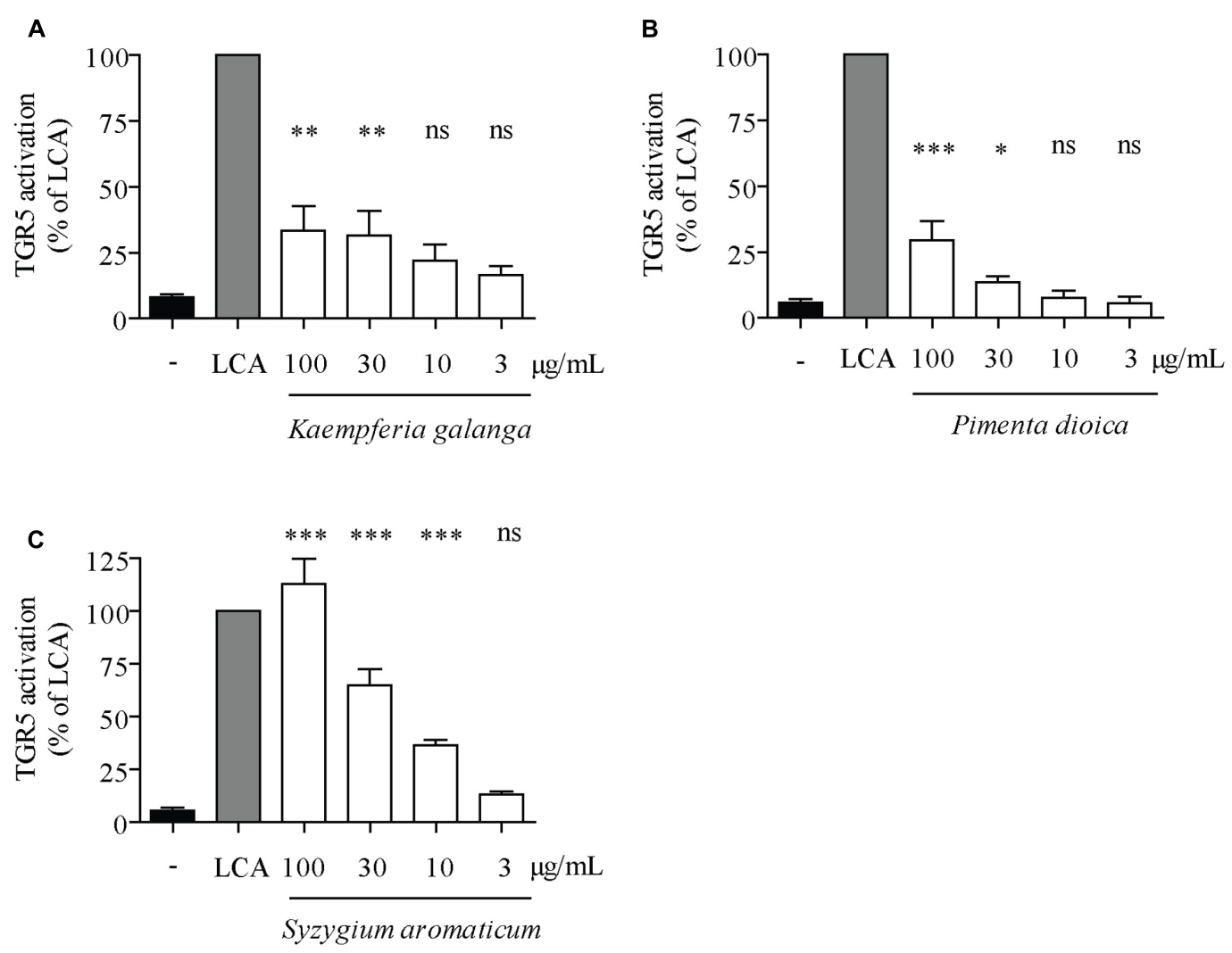

FIGURE 2 | Concentration-response studies with plant extracts regarding TGR5 activity. HEK-293 cells were cotransfected with a TGR5 expression plasmid, a CRE luciferase reporter plasmid and an EGFP plasmid as internal control. Cells were treated with $10 \mu \mathrm{M}$ lithocholic acid (LCA) as positive control or the indicated concentrations of (A) PdioE, (B) SaroE, or (C) KgalE for $18 \mathrm{~h}$. The measured luciferase-derived luminescence was normalized to the obtained EGFP-derived fluorescence. Results are expressed as \% activation compared to the reference LCA. Each bar represents the mean \pm SD of at least three independent experiments performed in quadruplicate and evaluated by one-way ANOVA with the Bonferroni post-test. ${ }^{* * *} p<0.001,{ }^{* *} p<0.01,{ }^{*} p<0.05$ compared with solvent vehicle control (DMSO), ns not significant versus DMSO.

TABLE 2 | EC 50 and $E_{\max }$ values of extracts from $P$. dioica (PdioE), S. aromaticum (SaroE), and K. galanga (KgalE) compared to chenodeoxycholic acid (CDCA).

\begin{tabular}{lcc}
\hline & $\mathbf{E C}_{\mathbf{5 0}}(\boldsymbol{\mu} \mathbf{g} / \mathbf{m L})$ or $(\boldsymbol{\mu} \mathbf{M})^{*}$ & $\boldsymbol{E}_{\max }(\% \mathbf{L C A})$ \\
\hline PdioE & $60.2 \pm 13.7$ & $29.5 \pm 8.3$ \\
SaroE & $19.8 \pm 16.6$ & $112.8 \pm 12.9$ \\
KgalE & $12.9 \pm 24.1$ & $33.2 \pm 9.4$ \\
CDCA & $33.2 \pm 4.5^{*}$ & $34.6 \pm 8.6$ \\
\hline
\end{tabular}

The HPLC-DAD-CAD and LC-MS analyses of KgalE indicated the presence of essential oil ingredients (Supplementary Figure S2) with the main component ethyl $p$-methoxycinnamate and the less abundant ethyl cinnamate (Wong et al., 1992; Raina and Abraham, 2016). Related derivatives, such as the corresponding propyl-esters and $p$-methoxycinnamic acid as well as fatty acid derivatives and minor unknown compounds were additionally detected (Table 3 ). Since none of these constituents have been described as TGR5 activators or are structurally similar to known TGR5 binders, KgalE was fractionated by RP-18 column chromatography to further assign the observed activity to a specific compound class or constituent. GC-MS analysis of the essential oil, which was obtained by steam distillation, revealed $92.2 \%$-methoxycinnamate and $1.3 \%$ ethyl cinnamate. The obtained six fractions as well as the steam distilled essential oil of $K$. galanga rhizomes were retested in the TGR5 luciferase reporter gene assay. Interestingly, the TGR5 activity was found to be distributed mainly between the essential oil and fractions 4 and 5 of KgalE (Figure 4). Thereby, the previously observed TGR5-activating potential of the extract could not be acuminated in one of these fractions. Moreover, the bioactive fractions negatively influenced cell viability, therefore we refrained from further separation and isolation of their constituents.

The extracts of $S$. aromaticum (SaroE) and $P$. dioica (PdioE) shared some similarities in their phytochemical profile (Tables 3, 4). Both samples contained some volatile and non-volatile phenolic compounds, such as isobiflorin, biflorin, eugenol, and acetyleugenol in SaroE, several dihydroxyeugenol derivatives and ericifolin in PdioE, and gallic acid in both. More importantly, TTAs were identified as major constituents of the extracts. The common monohydroxy TTAs betulinic, oleanolic, and ursolic acid were found to activate TGR5 with $\mathrm{EC}_{50}$ values in the range of $1-3 \mu \mathrm{M}$ in previous studies 


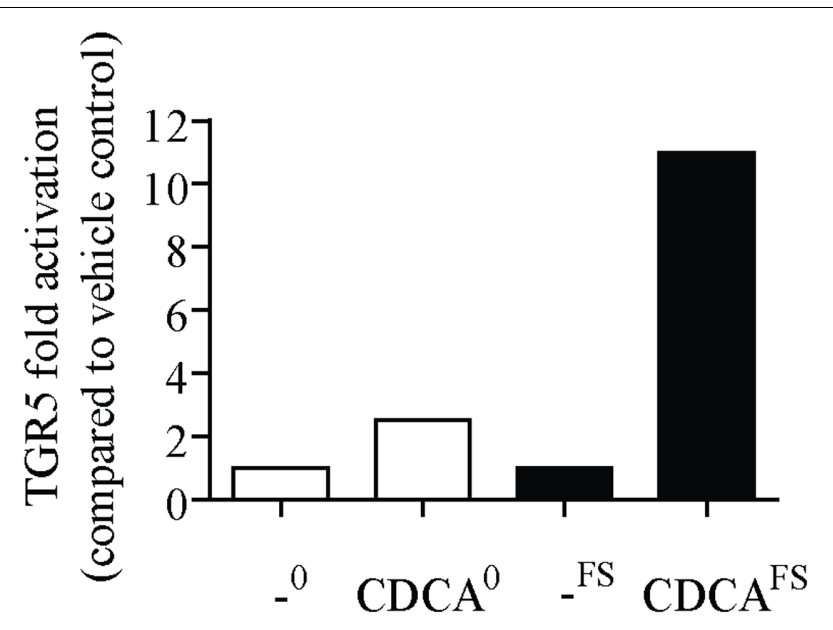

FIGURE 3 | Microbial transformation of chenodeoxycholic acid (CDCA) to lithocholic acid (LCA) increases TGR5 activity. CDCA was incubated with $\left(\mathrm{CDCA}^{\mathrm{FS}}\right)$ or without fecal microbiota $\left(\mathrm{CDCA}^{0}\right)$ from mice for $24 \mathrm{~h}$.

Corresponding vehicle controls are labeled "_FS" and "-0", respectively. After centrifugation and sterile filtration, a TGR5 luciferase reporter gene assay was performed as described in the Section "Materials and Methods." Cells were treated with $50 \mu \mathrm{M}$ of $\mathrm{CDCA}^{0}$ and $\mathrm{CDCA}^{\mathrm{FS}}$, respectively, for $18 \mathrm{~h}$. The measured luciferase-derived luminescence was normalized to the obtained EGFP-derived fluorescence. Results are expressed as fold activation compared to the vehicle control. Each bar represents one experiment performed in octuplicates.

(Sato et al., 2007; Genet et al., 2010). Indeed, comparison with reference compounds revealed oleanolic acid as the base peak in the CAD chromatogram of SaroE and both, oleanolic and ursolic acids as major constituents of PdioE. In addition, maslinic acid (in SaroE and PdioE) and corosolic acid (in PdioE), which are the $2 \alpha$-hydroxy-derivatives of oleanolic acid and ursolic acid, respectively, were identified as prominent ingredients of these two extracts (Figure 1). Whether and how the additional hydroxy-group in $2 \alpha$-position affects the activity on TGR5 has not been assessed so far.

\section{Quantification and TGR5 Activation of the Triterpene Acids}

To verify the assumption that the measured TGR5 activity of SaroE and PdioE can be related to the identified pentacyclic TTAs, we developed a quantitative HPLC-CAD method with external standardization to determine their concentration in the tested extracts. Our method showed good linearity in the range of $2-100 \mu \mathrm{g} / \mathrm{mL}$ for each of the four compounds. SaroE was found to contain $6.56 \pm 0.20 \%$ oleanolic acid and $2.70 \pm 0.04 \%$ maslinic acid. In correlation with the lower activity, the concentration of the TTAs was less in PdioE, namely $0.290 \pm 0.019 \%$ maslinic acid, $0.256 \pm 0.012 \%$ ursolic acid, $0.198 \pm 0.010 \%$ corosolic acid, and $0.148 \pm 0.007 \%$ oleanolic acid. Based on these quantification results, reconstituted mixtures of the identified TTAs were prepared in the same concentration and composition as in the final test concentration $(100 \mu \mathrm{g} / \mathrm{mL})$ of SaroE, i.e., $14.4 \mu \mathrm{M}$ oleanolic acid and $5.72 \mu \mathrm{M}$ maslinic acid, and PdioE, i.e., $0.32 \mu \mathrm{M}$ oleanolic acid, $0.61 \mu \mathrm{M}$ maslinic acid, $0.42 \mu \mathrm{M}$ corosolic acid, and $0.56 \mu \mathrm{M}$ ursolic acid. These reconstituted mixtures, together with the individual pure compounds, were tested in the TGR5 luciferase reporter gene assay. In both cases, the reconstituted mixtures of TTAs were equally potent compared to the respective extracts (Figure 5). The $\mathrm{EC}_{50}$ and $E_{\max }$ values of the extracts, the reconstituted mixtures and the single compounds are listed in Table 6.

\section{DISCUSSION}

Multi-component herbal preparations are widely used in traditional medicines. Deciphering whether the activity of such a complex mixture can be attributed to individual constituents is a widespread research interest.

In the present study, we investigated 19 plant extracts from a traditional Tibetan formula used against several symptoms related to the metabolic syndrome for their TGR5-activating potential. Out of these extracts, we identified three which were able to significantly upregulate TGR5 activity in a cell-based

TABLE 3 | Proposed structure, retention time, HRMS data, and predicted sum formulas of the compounds tentatively identified in the extract of the dried flower buds of Syzygium aromaticum (SaroE).

\begin{tabular}{|c|c|c|c|c|c|}
\hline$\#$ & Proposed structure & $\mathbf{R}_{\mathrm{t}}(\min )$ & {$[\mathbf{M}+\mathbf{H}]^{+}$} & {$[\mathrm{M}-\mathrm{H}]^{-}$} & Sum formula \\
\hline S1 & Gallic acid & 2.4 & 171.0300 & 169.0146 & $\mathrm{C}_{7} \mathrm{H}_{6} \mathrm{O}_{5}$ \\
\hline S2 & Isobiflorin & 5.5 & 355.1046 & 353.0889 & $\mathrm{C}_{16} \mathrm{H}_{18} \mathrm{O}_{9}$ \\
\hline S3 & Biflorin & 5.9 & 355.1045 & 353.0889 & $\mathrm{C}_{16} \mathrm{H}_{18} \mathrm{O}_{9}$ \\
\hline S4 & Eugenol & 16.1 & 165.0921 & n.d. & $\mathrm{C}_{10} \mathrm{H}_{12} \mathrm{O}_{2}$ \\
\hline S5 & Trihydroxy triterpene acid & 17.5 & 489.3574 & 487.3440 & $\mathrm{C}_{30} \mathrm{H}_{48} \mathrm{O}_{5}$ \\
\hline S6 & Acetyleugenol & 18.2 & 207.1029 & n.d. & $\mathrm{C}_{12} \mathrm{H}_{14} \mathrm{O}_{3}$ \\
\hline S7 & Maslinic acid & 21.1 & 473.3647 & 471.3492 & $\mathrm{C}_{30} \mathrm{H}_{48} \mathrm{O}_{4}$ \\
\hline S8 & Coumaroylmaslinic acid & 24.6 & 619.4007 & 617.3861 & $\mathrm{C}_{39} \mathrm{H}_{54} \mathrm{O}_{6}$ \\
\hline s9 & Oleanolic acid & 26.6 & 457.3689 & 455.3541 & $\mathrm{C}_{30} \mathrm{H}_{48} \mathrm{O}_{3}$ \\
\hline $\mathrm{S} 10$ & Linoleic acid & 28.5 & n.d. & 279.2340 & $\mathrm{C}_{18} \mathrm{H}_{32} \mathrm{O}_{2}$ \\
\hline $\mathrm{S} 11$ & Palmitic acid & 31.0 & n.d. & 255.2337 & $\mathrm{C}_{16} \mathrm{H}_{32} \mathrm{O}_{2}$ \\
\hline $\mathrm{S} 12$ & Oleic acid & 31.4 & n.d. & 281.2495 & $\mathrm{C}_{18} \mathrm{H}_{34} \mathrm{O}_{2}$ \\
\hline $\mathrm{S} 13$ & Stearic acid & 34.3 & n.d. & 283.2650 & $\mathrm{C}_{18} \mathrm{H}_{36} \mathrm{O}_{2}$ \\
\hline
\end{tabular}


TABLE 4 | Proposed structure, retention time, HRMS data, and predicted sum formulas of the compounds tentatively identified in the extract of the unripe fruits of Pimenta dioica (PdioE).

\begin{tabular}{|c|c|c|c|c|c|}
\hline$\#$ & Proposed structure & $\mathbf{R}_{\mathrm{t}}$ (min) & {$[\mathbf{M}+\mathbf{H}]^{+}$} & {$[\mathrm{M}-\mathrm{H}]^{-}$} & Sum formula \\
\hline P1 & Gallic acid & 2.4 & 171.0299 & 169.0148 & $\mathrm{C}_{7} \mathrm{H}_{6} \mathrm{O}_{5}$ \\
\hline P2 & Hexosylated derivative of P4 & 4.8 & 361.1504 & 359.1359 & $\mathrm{C}_{16} \mathrm{H}_{24} \mathrm{O}_{9}$ \\
\hline P3 & Hexosylated derivative of P4 & 5.1 & 361.1502 & 359.1360 & $\mathrm{C}_{16} \mathrm{H}_{24} \mathrm{O}_{9}$ \\
\hline P4 & $2^{\prime}, 3^{\prime}$-Dihydro-2',3'-dihydroxyeugenol & 5.1 & n.d. ${ }^{1}$ & 197.0825 & $\mathrm{C}_{10} \mathrm{H}_{14} \mathrm{O}_{4}$ \\
\hline P5 & - & 7.9 & 389.1821 & 387.1677 & $\mathrm{C}_{18} \mathrm{H}_{28} \mathrm{O}_{9}$ \\
\hline P6 & - & 9.1 & 227.1296 & 225.1140 & $\mathrm{C}_{12} \mathrm{H}_{18} \mathrm{O}_{4}$ \\
\hline P7 & Ericifolin & 14.3 & 495.1524 & 493.1373 & $\mathrm{C}_{23} \mathrm{H}_{26} \mathrm{O}_{12}$ \\
\hline P8 & Maslinic acid & 27.5 & 473.3648 & 471.3500 & $\mathrm{C}_{30} \mathrm{H}_{48} \mathrm{O}_{4}$ \\
\hline P9 & Corosolic acid & 27.8 & 473.3648 & 471.3502 & $\mathrm{C}_{30} \mathrm{H}_{48} \mathrm{O}_{4}$ \\
\hline P10 & Linolenic acid & 31.9 & 279.2334 & 277.2188 & $\mathrm{C}_{18} \mathrm{H}_{30} \mathrm{O}_{2}$ \\
\hline P11 & Oleanolic acid & 32.4 & 457.3689 & 455.3545 & $\mathrm{C}_{30} \mathrm{H}_{48} \mathrm{O}_{3}$ \\
\hline P12 & Ursolic acid & 32.4 & 457.3689 & 455.3545 & $\mathrm{C}_{30} \mathrm{H}_{48} \mathrm{O}_{3}$ \\
\hline P13 & Linoleic acid & 34.1 & 281.2491 & 279.2342 & $\mathrm{C}_{18} \mathrm{H}_{32} \mathrm{O}_{2}$ \\
\hline P14 & Palmitic acid & 36.4 & 257.2493 & 255.2341 & $\mathrm{C}_{16} \mathrm{H}_{32} \mathrm{O}_{2}$ \\
\hline P15 & Oleic acid & 36.7 & n.d. & 281.2499 & $\mathrm{C}_{18} \mathrm{H}_{34} \mathrm{O}_{2}$ \\
\hline P16 & Stearic acid & 39.9 & n.d. & 283.2653 & $\mathrm{C}_{18} \mathrm{H}_{36} \mathrm{O}_{2}$ \\
\hline
\end{tabular}

${ }^{1}$ The $[\mathrm{M}+\mathrm{Na}]^{+}$at $\mathrm{m} / \mathrm{z} 221.0797$ was detected instead.

TABLE 5 | Proposed structure, retention time, HRMS data and predicted sum formulas of the compounds tentatively identified in the extract of the rhizomes of Kaempferia galanga (KgalE).

\begin{tabular}{|c|c|c|c|c|c|}
\hline \# & Proposed structure & $\mathbf{R}_{\mathrm{t}}(\min )$ & {$[\mathbf{M}+\mathbf{H}]^{+}$} & {$[\mathbf{M}-\mathbf{H}]^{-}$} & Sum formula \\
\hline $\mathrm{K} 1$ & 4-Methoxycinnamic acid & 15.2 & 179.0716 & 177.0552 & $\mathrm{C}_{10} \mathrm{H}_{10} \mathrm{O}_{3}$ \\
\hline $\mathrm{K} 2$ & 4-Hydroxycinnamic acid ethyl ester & 17.8 & n.d. & 191.0711 & $\mathrm{C}_{11} \mathrm{H}_{12} \mathrm{O}_{3}$ \\
\hline K3 & 3,4-Dimethoxycinnamic acid ethyl ester & 21.4 & 237.1144 & n.d. & $\mathrm{C}_{13} \mathrm{H}_{16} \mathrm{O}_{4}$ \\
\hline $\mathrm{K} 4$ & 4-Hydroxycinnamic acid propyl ester & 23.1 & 207.1035 & n.d. & $\mathrm{C}_{12} \mathrm{H}_{14} \mathrm{O}_{3}$ \\
\hline K5 & 4-Methoxycinnamic acid ethyl ester & 24.5 & 207.1036 & n.d. & $\mathrm{C}_{12} \mathrm{H}_{14} \mathrm{O}_{3}$ \\
\hline K6 & - & 27.0 & 231.1400 & n.d. & $\mathrm{C}_{15} \mathrm{H}_{18} \mathrm{O}_{2}$ \\
\hline $\mathrm{K} 7$ & - & 27.3 & n.d. & 723.3802 & $\mathrm{C}_{34} \mathrm{H}_{60} \mathrm{O}_{16}$ \\
\hline K8 & Linoleoyl-glycero-3-phosphocholine & 27.9 & 520.3429 & n.d. ${ }^{1}$ & $\mathrm{C}_{26} \mathrm{H}_{51} \mathrm{NO}_{7} \mathrm{P}$ \\
\hline K9 & Linoleic acid & 39.9 & 281.2497 & 279.2331 & $\mathrm{C}_{18} \mathrm{H}_{32} \mathrm{O}_{2}$ \\
\hline $\mathrm{K} 10$ & Palmitic acid & 42.6 & n.d. & 255.2331 & $\mathrm{C}_{16} \mathrm{H}_{32} \mathrm{O}_{2}$ \\
\hline $\mathrm{K} 11$ & Oleic acid & 43.1 & n.d. & 281.2487 & $\mathrm{C}_{18} \mathrm{H}_{34} \mathrm{O}_{2}$ \\
\hline $\mathrm{K} 12$ & Stearic acid & 46.6 & n.d. & 283.2645 & $\mathrm{C}_{18} \mathrm{H}_{36} \mathrm{O}_{2}$ \\
\hline
\end{tabular}

${ }^{1}$ The $\left[\mathrm{M}+\mathrm{HCOO}^{-}\right.$at $\mathrm{m} / \mathrm{z} 564.3304$ was detected instead.

luciferase reporter gene assay. Interestingly, the active extracts, SaroE, PdioE, and KgalE, are derived from the three commonly used spices, namely clove (flower buds of $S$. aromaticum), allspice ( $P$. dioica), and aromatic ginger (rhizome of $K$. galanga), respectively.

Among them, SaroE activated TGR5 at $100 \mu \mathrm{g} / \mathrm{mL}$ even stronger than the positive control LCA at $10 \mu \mathrm{M}$. S. aromaticum extracts and its triterpene constituents have been reported to elicit many beneficial effects, for instance antihyperglycemic, antihyperlipidemic, and antioxidant activity as well as a reduced formation of cholesterol micelles in vitro (Sompong et al., 2016). Furthermore, the $S$. aromaticum-derived triterpenes oleanolic acid and maslinic acid have been shown to improve glucose homeostasis and suppress postprandial hyperglycemia in diabetic rats via inhibition of carbohydrate hydrolysis and reduction of glucose transporters in the gastrointestinal tract (Khathi et al.,
2013). The other two plant extracts activating TGR5 in our assay system are PdioE and KgalE. Extracts from $P$. dioica have been reported to have hypotensive activity (Suarez et al., 1997). Moreover, traditional use for $P$. dioica suggests a beneficial effect for gastrointestinal and metabolic disorders as it is used for dyspepsia and diabetes, to relieve indigestion and as purgative in different folk medicines (Zhang and Lokeshwar, 2012). K. galanga extracts have been shown to act anti-inflammatory (Jagadish et al., 2016) and its constituent ethyl cinnamate is reported to have vasorelaxant activity (Othman et al., 2006). Activation of TGR 5 could play a role in several of these reported activities.

In the last years, the role of the gut microbiome in the metabolism and transformation of dietary compounds and orally administered pharmaceuticals gained more and more attention (Marin et al., 2015; Li H. et al., 2016; Sonnenburg and Backhed, 2016; Zhang and Davies, 2016). Naturally occurring gut 


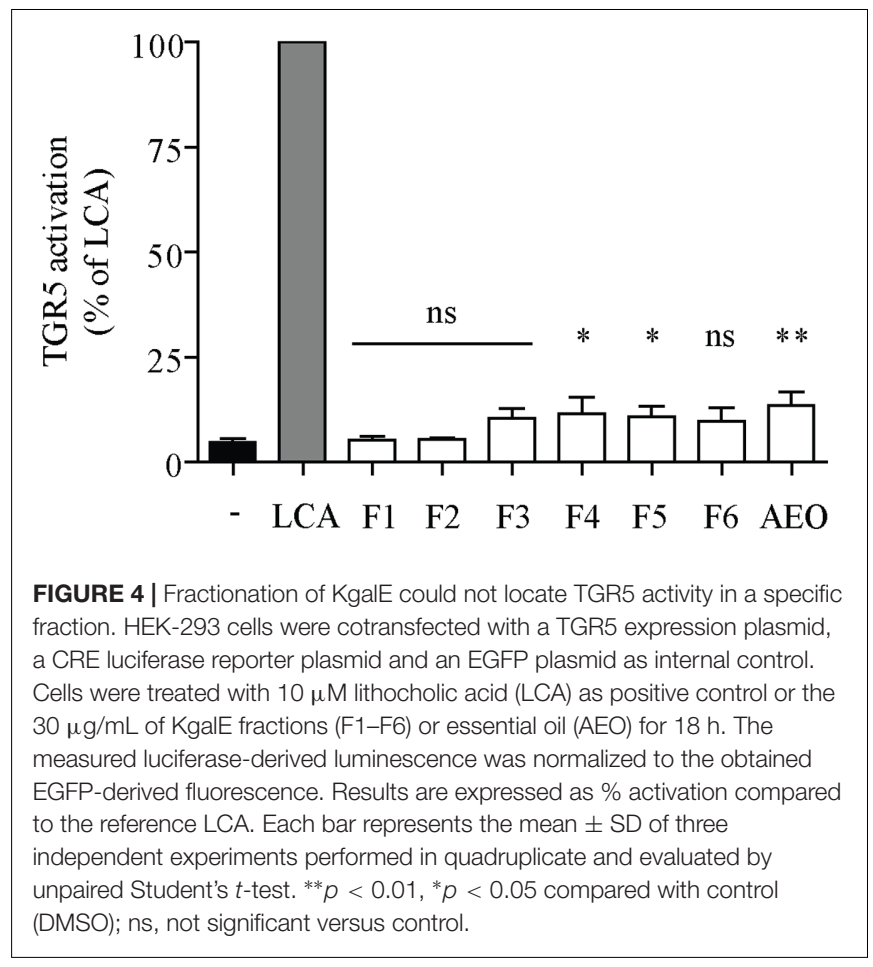

metabolites of dietary sources or herbal medicinal preparations may be the active principles of many ethnopharmacologically used preparations. Many traditional herbal remedies are used orally: After ingestion, ingredients are released, occasionally metabolized, and then absorbed via the gut. Once in the blood stream, constituents can enter other tissues to interact with
TABLE 6 | $\mathrm{EC}_{50}$ and $E_{\max }$ values of indicated extracts, reconstituted mixtures of TTAs and pure compounds.

\begin{tabular}{lcc}
\hline & $\mathbf{E C}_{\mathbf{5 0}}(\boldsymbol{\mu} \mathbf{g} / \mathbf{m L})$ or $(\boldsymbol{\mu} \mathbf{M})^{*}$ & $\boldsymbol{E}_{\max }(\% \mathbf{L C A})$ \\
\hline SaroE & $19.8 \pm 16.6$ & $112.8 \pm 12.9$ \\
PdioE & $60.2 \pm 13.7$ & $29.5 \pm 8.3$ \\
ПTA (SaroE) & $40.7 \pm 40.1$ & $93.7 \pm 16.2$ \\
ПTA (PdioE) & $80.7 \pm 36.6$ & $23.6 \pm 9.3$ \\
Oleanolic acid & $2.2 \pm 1.6^{*}$ & $62.6 \pm 14.9$ \\
Maslinic acid & $3.7 \pm 0.7^{*}$ & $29.2 \pm 5.0$ \\
Corosolic acid & $0.5 \pm 1.0^{*}$ & $9.8 \pm 3.3$ \\
Ursolic acid & $1.1 \pm 0.2^{*}$ & $19.6 \pm 14.2$
\end{tabular}

respective signal transduction pathways. Apart from this view, oral medicines may also be able to interact with receptors present in gastrointestinal cells thereby eliciting systemic effects without entering the blood stream (Reimann et al., 2012). This also renders the effect of pharmaceuticals independent on bioavailability. As orally administered herbal preparations are able to reach their highest concentration locally in the gut, membrane receptors like TGR5 are likely targets. Furthermore, constituents can be transformed by the microbiome present in the gut yielding active metabolites. An example for such an action is the transformation of CDCA to LCA. CDCA activates FXR in the ileum but after bacterial transformation to LCA it is a far better activator for TGR5 localized mainly in intestinal L-cells in the large intestine (Hirano et al., 1981).

To study a possible microbial transformation of extract constituents, we incubated the three TGR5-activating plant

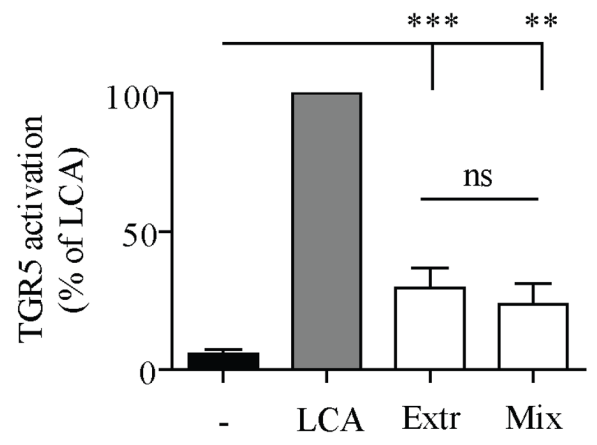

Pimenta dioica

$100 \mu \mathrm{g} / \mathrm{mL}$

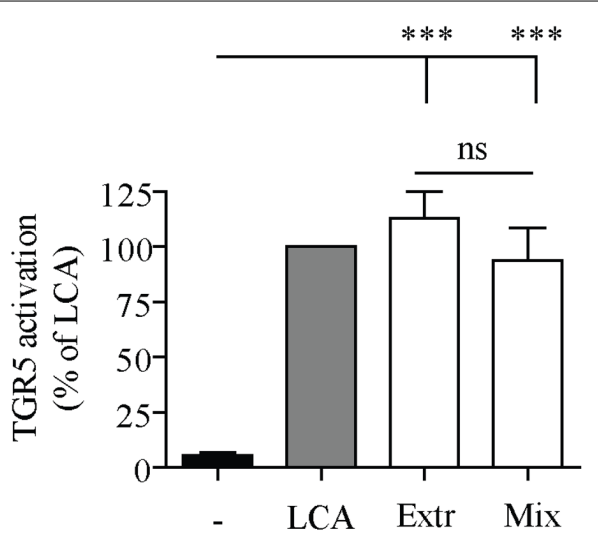

Syzygium aromaticum

$100 \mu \mathrm{g} / \mathrm{mL}$

FIGURE 5 | Pentacyclic triterpene acids in the extracts of S. aromaticum (SaroE) and P. dioica (PdioE) are the components activating TGR5. HEK-293 cells were cotransfected with a TGR5 expression plasmid, a CRE luciferase reporter plasmid and an EGFP plasmid as internal control. Cells were treated with $10 \mu \mathrm{M}$ lithocholic acid (LCA) as positive control or $100 \mu \mathrm{g} / \mathrm{mL}$ of extracts (Extr) or reconstituted TTA mixtures (Mix) for $18 \mathrm{~h}$. The measured luciferase-derived luminescence was normalized to the obtained EGFP-derived fluorescence. Results are expressed as \% activation compared to the reference LCA. Each bar represents the mean \pm SD of four independent experiments performed in quadruplicate and evaluated by unpaired Student's $t$-test. ${ }^{* * *} p<0.001$, ${ }^{* *} p<0.01$ compared with solvent vehicle control (DMSO); ns, not significant versus indicated group. 
extracts SaroE, PdioE, and KgalE with mouse fecal microbiota. The transformation of CDCA to LCA by incubation with fecal samples from mice was used to validate our assay system. Instrumental analysis revealed that only PdioE and KgalE but not SaroE showed a changed metabolite profile after transformation. Retesting of the transformed PdioE and KgalE extracts, however, did not alter the TGR5 activation profile. We therefore focused on the identification of non-transformed constituents in SaroE, KgalE, and PdioE.

Dereplication, quantification, and retesting of the extracts' constituents clearly deciphered TTAs as the only TGR5 effectors in the multicomponent mixtures of SaroE and PdioE. Analysis and retesting of KgalE fractions, however, could not trace back the activity exclusively to a specific compound or compound class suggesting an interaction of several constituents, such as volatile and non-volatile phenylpropanoids, that contribute to the observed effect.

Whereas oleanolic acid and ursolic acid have already been reported to activate TGR5 with $\mathrm{EC}_{50}$ values between 1 and $3 \mu \mathrm{M}$ (Sato et al., 2007; Genet et al., 2010), we could further ascribe the TGR5-upregulating activity to the TTAs corosolic acid and maslinic acid. Many studies have been performed investigating corosolic acid (Miura et al., 2006; Yamaguchi et al., 2006; Yamada et al., 2007; Shi et al., 2008; Chen et al., 2012; Li et al., 2014; Li X.Q. et al., 2016; Yang et al., 2016) and maslinic acid (Wen et al., 2005, 2008; Liu et al., 2007, 2014; Guan et al., 2011; Khathi et al., 2013; Mkhwanazi et al., 2014; Hung et al., 2015) with regard to their beneficial impact on diabetes and the metabolic syndrome. In respect of the structural similarities to oleanolic acid and ursolic acid, maslinic acid and corosolic acid are likely to activate TGR5 in a similar manner.

Structure-activity studies of pentacyclic TTAs identified the C3-hydroxyl and the C28-carboxylate group as being of major importance for TGR5 activation. Oleanolic acid, ursolic acid, corosolic acid, and maslinic acid all contain these two features (Figure 1), thereby suggesting the same binding mode. It has been predicted that triterpenes bind TGR5 via three binding pockets. Recognition of the C3-hydroxyl group is accomplished via a narrow $\mathrm{H}$-bonding site. The pentacyclic skeleton is harbored in a hydrophobic pocket and a small polar site binds the free carboxylic acid (Genet et al., 2010; Castellano et al., 2013).

The fact that the only TGR5 agonist that has been studied in humans so far, SB-756050, has thus-far failed to be launched, underlines the need for TGR5 activators with a favorable benefit:risk ratio. SB-756050 elicited variable pharmacodynamic effects at different doses on circulating GLP-1 and PYY in humans. This was in contrast to results obtained in animals and questioned the general translatability to humans (Hodge et al., 2013). Moreover, intestinally targeted TGR5 agonists are at the moment discussed to be better suited

\section{REFERENCES}

Achuthan, C. R., and Padikkala, J. (1997). Hypolipidemic effect of Alpinia galanga (Rasna) and Kaempferia galanga (Kachoori). Indian J. Clin. Biochem. 12, 55-58. doi: 10.1007/BF02867956 for therapeutic use (Cao et al., 2016), making compounds with low oral bioavailability, like oleanolic acid, interesting (Jiang et al., 2016). In this respect, herbal remedies and food supplements may offer highly interesting sources for adequate concentrations of the hereby identified TTAs that are able to locally target and upregulate TGR5 in intestinal L-cells of the large intestine.

\section{CONCLUSION}

This is the first study that reports the TGR5-upregulating effect of the herbal remedies and condiments aromatic ginger, allspice, and clove. This may explain their therapeutic potential for the treatment of metabolic diseases. Moreover, the TGR5 activation of SaroE and PdioE could be pinpointed solely to the TTAs oleanolic acid and ursolic acid and the novel TGR5 agonists maslinic acid and corosolic acid.

\section{AUTHOR CONTRIBUTIONS}

JR, VD, DB, AL, and MZ conceived and designed the experiments. AL, $\mathrm{CH}, \mathrm{NF}$, and FP performed the experiments. $\mathrm{AL}, \mathrm{MZ}$, and UG analyzed the data. AL wrote the manuscript. $\mathrm{MZ}, \mathrm{UG}, \mathrm{VD}$, and JR critically revised the manuscript. All authors have contributed to the final version and approved the final manuscript.

\section{FUNDING}

This work was supported by the Austrian Science Fund (FWF): S10704 (NFN "Drugs from Nature Targeting Inflammation"). DB and FP were supported by the Austrian Science Fund (FWF; P27831-B28 and P26127-B20) and the European Union's Horizon 2020 Framework Programme for Research and Innovation (grant No. 658718 to FP).

\section{ACKNOWLEDGMENT}

We thank PADMA AG (Wetzikon, Switzerland) for providing the plant material free of charge.

\section{SUPPLEMENTARY MATERIAL}

The Supplementary Material for this article can be found online at: http://journal.frontiersin.org/article/10.3389/fphar. 2017.00468/full\#supplementary-material

Aron-Wisnewsky, J., Dore, J., and Clement, K. (2012). The importance of the gut microbiota after bariatric surgery. Nat. Rev. Gastroenterol. Hepatol. 9, 590-598. doi: $10.1038 /$ nrgastro.2012.161

Bala, V., Rajagopal, S., Kumar, D. P., Nalli, A. D., Mahavadi, S., Sanyal, A. J., et al. (2014). Release of GLP-1 and PYY in response to the activation of G 
protein-coupled bile acid receptor TGR5 is mediated by Epac/PLC-epsilon pathway and modulated by endogenous H2S. Front. Physiol. 5:420. doi: 10.3389/ fphys.2014.00420

Broeders, E. P., Nascimento, E. B., Havekes, B., Brans, B., Roumans, K. H., Tailleux, A., et al. (2015). The bile acid chenodeoxycholic acid increases human brown adipose tissue activity. Cell Metab. 22, 418-426. doi: 10.1016/j.cmet.2015. 07.002

Brunner-La Rocca, H. P., Schindler, R., Schlumpf, M., Saller, R., and Suter, M. (2005). Effects of the Tibetan herbal preparation PADMA 28 on blood lipids and lipid oxidisability in subjects with mild hypercholesterolaemia. VASA 34, 11-17. doi: 10.1024/0301-1526.34.1.11

Camp, D., Davis, R. A., Campitelli, M., Ebdon, J., and Quinn, R. J. (2012). Drug-like properties: guiding principles for the design of natural product libraries. J. Nat. Prod. 75, 72-81. doi: 10.1021/np200687v

Cao, H., Chen, Z. X., Wang, K., Ning, M. M., Zou, Q. A., Feng, Y., et al. (2016). Intestinally-targeted TGR5 agonists equipped with quaternary ammonium have an improved hypoglycemic effect and reduced gallbladder filling effect. Sci. Rep. 6:28676. doi: $10.1038 /$ srep28676

Castellano, J. M., Guinda, A., Delgado, T., Rada, M., and Cayuela, J. A. (2013). Biochemical basis of the antidiabetic activity of oleanolic acid and related pentacyclic triterpenes. Diabetes Metab. Res. Rev. 62, 1791-1799. doi: 10.2337/ db12-1215

Chen, H., Yang, J., Zhang, Q., Chen, L. H., and Wang, Q. (2012). Corosolic acid ameliorates atherosclerosis in apolipoprotein E-deficient mice by regulating the nuclear factor-kappaB signaling pathway and inhibiting monocyte chemoattractant protein-1 expression. Circ. J. 76, 995-1003.

Cortes-Rojas, D. F., de Souza, C. R., and Oliveira, W. P. (2014). Clove (Syzygium aromaticum): a precious spice. Asian Pac. J. Trop. Biomed. 4, 90-96. doi: 10.1016/S2221-1691(14)60215-X

Genet, C., Strehle, A., Schmidt, C., Boudjelal, G., Lobstein, A., Schoonjans, K., et al. (2010). Structure-activity relationship study of betulinic acid, a novel and selective TGR5 agonist, and its synthetic derivatives: potential impact in diabetes. J. Med. Chem. 53, 178-190. doi: 10.1021/jm900872z

Gerard, P. (2013). Metabolism of cholesterol and bile acids by the gut microbiota. Pathogens 3, 14-24. doi: 10.3390/pathogens3010014

Guan, T., Qian, Y., Tang, X., Huang, M., Huang, L., Li, Y., et al. (2011). Maslinic acid, a natural inhibitor of glycogen phosphorylase, reduces cerebral ischemic injury in hyperglycemic rats by GLT-1 up-regulation. J. Neurosci. Res. 89, 1829-1839. doi: 10.1002/jnr.22671

Harach, T., Pols, T. W., Nomura, M., Maida, A., Watanabe, M., Auwerx, J., et al. (2012). TGR5 potentiates GLP-1 secretion in response to anionic exchange resins. Sci. Rep. 2:430. doi: 10.1038/srep00430

Hirano, S., Masuda, N., and Oda, H. (1981). In vitro transformation of chenodeoxycholic acid and ursodeoxycholic acid by human intestinal flora, with particular reference to the mutual conversion between the two bile acids. J. Lipid Res. 22, 735-743.

Hodge, R. J., Lin, J., Vasist Johnson, L. S., Gould, E. P., Bowers, G. D., and Nunez, D. J. (2013). Safety, pharmacokinetics, and pharmacodynamic effects of a selective TGR5 agonist, SB-756050, in type 2 diabetes. Clin. Pharmacol. Drug Dev. 2, 213-222. doi: 10.1002/cpdd.34

Hung, Y. C., Yang, H. T., and Yin, M. C. (2015). Asiatic acid and maslinic acid protected heart via anti-glycative and anti-coagulatory activities in diabetic mice. Food Funct. 6, 2967-2974. doi: 10.1039/c5fo00549c

Jagadish, P. C., Latha, K. P., Mudgal, J., and Nampurath, G. K. (2016). Extraction, characterization and evaluation of Kaempferia galanga L. (Zingiberaceae) rhizome extracts against acute and chronic inflammation in rats. J. Ethnopharmacol. 194, 434-439. doi: 10.1016/j.jep.2016. 10.010

Jiang, Q., Yang, X., Du, P., Zhang, H., and Zhang, T. (2016). Dual strategies to improve oral bioavailability of oleanolic acid: enhancing water-solubility, permeability and inhibiting cytochrome $\mathrm{P} 450$ isozymes. Eur. J. Pharm. Biopharm. 99, 65-72. doi: 10.1016/j.ejpb.2015.11.013

Kawamata, Y., Fujii, R., Hosoya, M., Harada, M., Yoshida, H., Miwa, M., et al. (2003). A G protein-coupled receptor responsive to bile acids. J. Biol. Chem. 278, 9435-9440. doi: 10.1074/jbc.M209706200

Khathi, A., Serumula, M. R., Myburg, R. B., Van Heerden, F. R., and Musabayane, C. T. (2013). Effects of Syzygium aromaticum-derived triterpenes on postprandial blood glucose in streptozotocin-induced diabetic rats following carbohydrate challenge. PLOS ONE 8:e81632. doi: 10.1371/journal.pone. 0081632

Kratz, J. M., Mair, C. E., Oettl, S. K., Saxena, P., Scheel, O., Schuster, D., et al. (2016). hERG channel blocking ipecac alkaloids identified by combined in silico - in vitro screening. Planta Med. 82, 1009-1015. doi: 10.1055/s-0042- 105572

Kumar, D. P., Rajagopal, S., Mahavadi, S., Mirshahi, F., Grider, J. R., Murthy, K. S., et al. (2012). Activation of transmembrane bile acid receptor TGR5 stimulates insulin secretion in pancreatic beta cells. Biochem. Biophys. Res. Commun. 427, 600-605. doi: 10.1016/j.bbrc.2012.09.104

Kumar, K. M., Asish, G. R., Sabu, M., and Balachandran, I. (2013). Significance of gingers (Zingiberaceae) in Indian system of medicine - ayurveda: an overview. Anc. Sci. Life 32, 253-261. doi: 10.4103/0257-7941.131989

Li, H., He, J., and Jia, W. (2016). The influence of gut microbiota on drug metabolism and toxicity. Expert Opin. Drug Metab. Toxicol. 12, 31-40. doi: 10.1517/17425255.2016.1121234

Li, X. Q., Tian, W., Liu, X. X., Zhang, K., Huo, J. C., Liu, W. J., et al. (2016). Corosolic acid inhibits the proliferation of glomerular mesangial cells and protects against diabetic renal damage. Sci. Rep. 6:26854. doi: 10.1038/ srep26854

Li, T., Holmstrom, S. R., Kir, S., Umetani, M., Schmidt, D. R., Kliewer, S. A., et al. (2011). The G protein-coupled bile acid receptor, TGR5, stimulates gallbladder filling. Mol. Endocrinol. 25, 1066-1071. doi: 10.1210/me.2010-0460

Li, Y., Li, J. J., Wen, X. D., Pan, R., He, Y. S., and Yang, J. (2014). Metabonomic analysis of the therapeutic effect of Potentilla discolor in the treatment of type 2 diabetes mellitus. Mol. Biosyst. 10, 2898-2906. doi: 10.1039/c4mb00278d

Liu, J., Sun, H., Duan, W., Mu, D., and Zhang, L. (2007). Maslinic acid reduces blood glucose in KK-Ay mice. Biol. Pharm. Bull. 30, 2075-2078.

Liu, J., Wang, X., Chen, Y. P., Mao, L. F., Shang, J., Sun, H. B., et al. (2014). Maslinic acid modulates glycogen metabolism by enhancing the insulin signaling pathway and inhibiting glycogen phosphorylase. Chin. J. Nat. Med. 12, 259-265. doi: 10.1016/S1875-5364(14)60052-2

Marin, L., Miguelez, E. M., Villar, C. J., and Lombo, F. (2015). Bioavailability of dietary polyphenols and gut microbiota metabolism: antimicrobial properties. BioMed. Res. Int. 2015:905215. doi: 10.1155/2015/905215

Maruyama, T., Tanaka, K., Suzuki, J., Miyoshi, H., Harada, N., Nakamura, T., et al. (2006). Targeted disruption of $\mathrm{G}$ protein-coupled bile acid receptor 1 (Gpbar1/M-Bar) in mice. J. Endocrinol. 191, 197-205. doi: 10.1677/joe.1.06546

Melzer, J., Brignoli, R., Diehm, C., Reichling, J., Do, D. D., and Saller, R. (2006). Treating intermittent claudication with Tibetan medicine Padma 28: Does it work? Atherosclerosis 189, 39-46. doi: 10.1016/j.atherosclerosis.2006.02.042

Melzer, J., and Saller, R. (2013). Clinical studies in peripheral arterial occlusive disease: update from the aspects of a meta-narrative review. Forsch. Komplementarmed. 20(Suppl. 2), 17-21. doi: 10.1159/000351720

Miura, T., Ueda, N., Yamada, K., Fukushima, M., Ishida, T., Kaneko, T., et al. (2006). Antidiabetic effects of corosolic acid in KK-Ay diabetic mice. Biol. Pharm. Bull. 29, 585-587.

Mkhwanazi, B. N., Serumula, M. R., Myburg, R. B., Van Heerden, F. R., and Musabayane, C. T. (2014). Antioxidant effects of maslinic acid in livers, hearts and kidneys of streptozotocin-induced diabetic rats: effects on kidney function. Renal Fail. 36, 419-431. doi: 10.3109/0886022X.2013.867799

Opara, E. I., and Chohan, M. (2014). Culinary herbs and spices: their bioactive properties, the contribution of polyphenols and the challenges in deducing their true health benefits. Int. J. Mol. Sci. 15, 19183-19202. doi: 10.3390/ ijms 151019183

Othman, R., Ibrahim, H., Mohd, M. A., Mustafa, M. R., and Awang, K. (2006). Bioassay-guided isolation of a vasorelaxant active compound from Kaempferia galanga L. Phytomedicine 13, 61-66. doi: 10.1016/j.phymed.2004.07.004

Perino, A., and Schoonjans, K. (2015). TGR5 and immunometabolism: insights from physiology and pharmacology. Trends Pharm. Sci. 36, 847-857. doi: 10.1016/j.tips.2015.08.002

Poole, D. P., Godfrey, C., Cattaruzza, F., Cottrell, G. S., Kirkland, J. G., Pelayo, J. C., et al. (2010). Expression and function of the bile acid receptor GpBAR1 (TGR5) in the murine enteric nervous system. Neurogastroenterol. Motil. 22, 814-825, e227-e818. doi: 10.1111/j.1365-2982.2010.01487.x

Possemiers, S., Bolca, S., Verstraete, W., and Heyerick, A. (2011). The intestinal microbiome: a separate organ inside the body with the metabolic potential to influence the bioactivity of botanicals. Fitoterapia 82, 53-66. doi: 10.1016/j. fitote.2010.07.012 
Raina, A. P., and Abraham, Z. (2016). Chemical profiling of essential oil of Kaempferia galanga L. germplasm from India. J. Essent. Oil Res. 28, 29-34. doi: 10.1080/10412905.2015.1077165

Reimann, F., Tolhurst, G., and Gribble, F. M. (2012). G-protein-coupled receptors in intestinal chemosensation. Cell Metab. 15, 421-431. doi: 10.1016/j.cmet.2011. 12.019

Saha, S., Rajpal, D. K., and Brown, J. R. (2016). Human microbial metabolites as a source of new drugs. Drug Discov. Today 21, 692-698. doi: 10.1016/j.drudis. 2016.02.009

Sanae, F., Kamiyama, O., Ikeda-Obatake, K., Higashi, Y., Asano, N., Adachi, I., et al. (2014). Effects of eugenol-reduced clove extract on glycogen phosphorylase b and the development of diabetes in db/db mice. Food Funct. 5, 214-219. doi: $10.1039 / \mathrm{c} 3$ fo6 $0514 \mathrm{k}$

Sato, H., Genet, C., Strehle, A., Thomas, C., Lobstein, A., Wagner, A., et al. (2007). Anti-hyperglycemic activity of a TGR5 agonist isolated from Olea europaea. Biochem. Biophys. Res. Commun. 362, 793-798. doi: 10.1016/j.bbrc.2007. 06.130

Schwabl, H., and Vennos, C. (2015). From medical tradition to traditional medicine: a Tibetan formula in the European framework. J. Ethnopharmacol. 167, 108-114. doi: 10.1016/j.jep.2014.10.033

Shamaladevi, N., Lyn, D. A., Shaaban, K. A., Zhang, L., Villate, S., Rohr, J., et al. (2013). Ericifolin: a novel antitumor compound from allspice that silences androgen receptor in prostate cancer. Carcinogenesis 34, 1822-1832. doi: $10.1093 /$ carcin/bgt123

Shi, L., Zhang, W., Zhou, Y. Y., Zhang, Y. N., Li, J. Y., Hu, L. H., et al. (2008). Corosolic acid stimulates glucose uptake via enhancing insulin receptor phosphorylation. Eur. J. Pharmacol. 584, 21-29. doi: 10.1016/j.ejphar.2008. 01.020

Sompong, W., Muangngam, N., Kongpatpharnich, A., Manacharoenlarp, C., Amorworasin, C., Suantawee, T., et al. (2016). The inhibitory activity of herbal medicines on the keys enzymes and steps related to carbohydrate and lipid digestion. BMC Complement. Altern. Med. 16:439. doi: 10.1186/s12906-0161424- 2

Sonnenburg, J. L., and Backhed, F. (2016). Diet-microbiota interactions as moderators of human metabolism. Nature 535, 56-64. doi: 10.1038/ nature 18846

Suarez, A., Ulate, G., and Ciccio, J. F. (1997). Cardiovascular effects of ethanolic and aqueous extracts of Pimenta dioica in Sprague-Dawley rats. J. Ethnopharmacol. 55, 107-111.

Svensson, P. A., Olsson, M., Andersson-Assarsson, J. C., Taube, M., Pereira, M. J., Froguel, P., et al. (2013). The TGR5 gene is expressed in human subcutaneous adipose tissue and is associated with obesity, weight loss and resting metabolic rate. Biochem. Biophys. Res. Commun. 433, 563-566. doi: 10.1016/j.bbrc.2013. 03.031

Thomas, C., Gioiello, A., Noriega, L., Strehle, A., Oury, J., Rizzo, G., et al. (2009). TGR5-mediated bile acid sensing controls glucose homeostasis. Cell Metab. 10, 167-177. doi: 10.1016/j.cmet.2009.08.001

Thomas, C., Pellicciari, R., Pruzanski, M., Auwerx, J., and Schoonjans, K. (2008). Targeting bile-acid signalling for metabolic diseases. Nat. Rev. Drug Discov. 7, 678-693. doi: 10.1038/nrd2619

Tu, Z., Moss-Pierce, T., Ford, P., and Jiang, T. A. (2014). Syzygium aromaticum L. (Clove) extract regulates energy metabolism in myocytes. J. Med. Food 17, 1003-1010. doi: 10.1089/jmf.2013.0175

Wang, X. X., Edelstein, M. H., Gafter, U., Qiu, L., Luo, Y., Dobrinskikh, E., et al. (2016). G protein-coupled bile acid receptor TGR5 activation inhibits kidney disease in obesity and diabetes. J. Am. Soc. Nephrol. 27, 1362-1378. doi: 10.1681/ASN.2014121271

Wang, Y. D., Chen, W. D., Yu, D., Forman, B. M., and Huang, W. (2011). The G-protein-coupled bile acid receptor, Gpbar1 (TGR5), negatively regulates hepatic inflammatory response through antagonizing nuclear factor kappa light-chain enhancer of activated B cells (NF-kappaB) in mice. Hepatology 54, 1421-1432. doi: 10.1002/hep. 24525

Watanabe, M., Houten, S. M., Mataki, C., Christoffolete, M. A., Kim, B. W., Sato, H., et al. (2006). Bile acids induce energy expenditure by promoting intracellular thyroid hormone activation. Nature 439, 484-489. doi: 10.1038/ nature 04330

Wen, X., Sun, H., Liu, J., Cheng, K., Zhang, P., Zhang, L., et al. (2008). Naturally occurring pentacyclic triterpenes as inhibitors of glycogen phosphorylase: synthesis, structure-activity relationships, and X-ray crystallographic studies. J. Med. Chem. 51, 3540-3554. doi: 10.1021/jm8000949

Wen, X., Sun, H., Liu, J., Wu, G., Zhang, L., Wu, X., et al. (2005). Pentacyclic triterpenes. Part 1: the first examples of naturally occurring pentacyclic triterpenes as a new class of inhibitors of glycogen phosphorylases. Bioorg. Med. Chem. Lett. 15, 4944-4948. doi: 10.1016/j.bmcl.2005.08.026

Wong, K. C., Ong, K. S., and Lim, C. L. (1992). Compositon of the essential oil of rhizomes of kaempferia galanga L. Flavour Fragr. J. 7, 263-266. doi: 10.1002/ffj.2730070506

Yamada, K., Hosokawa, M., Fujimoto, S., Nagashima, K., Fukuda, K., Fujiwara, H., et al. (2007). The spontaneously diabetic Torii rat with gastroenteropathy. Diabetes Res. Clin. Pract. 75, 127-134. doi: 10.1016/j.diabres.2006.06.034

Yamaguchi, Y., Yamada, K., Yoshikawa, N., Nakamura, K., Haginaka, J., and Kunitomo, M. (2006). Corosolic acid prevents oxidative stress, inflammation and hypertension in SHR/NDmcr-cp rats, a model of metabolic syndrome. Life Sci. 79, 2474-2479. doi: 10.1016/j.lfs.2006.08.007

Yang, J., Leng, J., Li, J. J., Tang, J. F., Li, Y., Liu, B. L., et al. (2016). Corosolic acid inhibits adipose tissue inflammation and ameliorates insulin resistance via AMPK activation in high-fat fed mice. Phytomedicine 23, 181-190. doi: 10.1016/j.phymed.2015.12.018

Yoneno, K., Hisamatsu, T., Shimamura, K., Kamada, N., Ichikawa, R., Kitazume, M. T., et al. (2013). TGR5 signalling inhibits the production of proinflammatory cytokines by in vitro differentiated inflammatory and intestinal macrophages in Crohn's disease. Immunology 139, 19-29. doi: 10.1111/imm. 12045

Zhang, L., and Lokeshwar, B. L. (2012). Medicinal properties of the Jamaican pepper plant Pimenta dioica and Allspice. Curr. Drug Targets 13, 1900-1906.

Zhang, L. S., and Davies, S. S. (2016). Microbial metabolism of dietary components to bioactive metabolites: opportunities for new therapeutic interventions. Genome Med. 8:46. doi: 10.1186/s13073-016-0296-x

Conflict of Interest Statement: The authors declare that the research was conducted in the absence of any commercial or financial relationships that could be construed as a potential conflict of interest.

Copyright (c) 2017 Ladurner, Zehl, Grienke, Hofstadler, Faur, Pereira, Berry, Dirsch and Rollinger. This is an open-access article distributed under the terms of the Creative Commons Attribution License (CC BY). The use, distribution or reproduction in other forums is permitted, provided the original author(s) or licensor are credited and that the original publication in this journal is cited, in accordance with accepted academic practice. No use, distribution or reproduction is permitted which does not comply with these terms. 